Periodical inspections in the field of all "clean" companies were undertaken, in order to detect and remove to " $Z$ " companies any cases of trachoma which had escaped detection at the first examination, and had developed subsequently.

These measures were extraordinarily successful in keeping down eye disease among the Chinese, and in minimizing the number of men off work from eye trouble. The number of men unable to work from this cause was infinitesimal; the average number of men off duty was between 0.025 and 0.09 per cent., and this was the same in the " $Z$ " and " $X$ " companies alike.

The freedom of the men affected with trachoma from serious complications, the prevention of the spread of the disease to the whole body of Chinese labourers, and the reduction of labour wastage from eye disease to such minute proportions, together constitute a noteworthy achievement in preventive medicine.

Even more important than this is the highly gratifying result that in no case, as far as we know, was the infection transferred to any white soldier or civilian from the large number of Chinese labourers suffering from trachoma.

Moreover, these Chinese themselves, as a result of the constant treatment and the education in ophthalmic hygiene, are in a very much better condition than they would have been if the disease had run its usual untreated course in their homeland. The ordinary sequelae-pannus, corneal ulceration, trichiasis and entropion (often culminating in blindness in one or both eyes) which are so terribly common in China, were very rare in these men. Not more than ten out of the body of eight thousand men in trachoma companies were repatriated on account of complications which disabled them from work.

We desire, in conclusion, to acknowledge the constant help given us in our work by Colonel W. T. Lister, Ophthalmic Consultant to the B.E.F., France, and by Lieutenant-Colonel G. D. Gray, the Commanding Officer of No. 3, Native Labour General Hospital, and their kind permission to publish the above record of our experience.

\title{
PERFORATING WOUNDS OF THE EYE
}

\section{An investigation of 106 cases occurring in Soldiers at a Military Ophthalmic Centre in London}

BY

\author{
GeORge MAXTeD, F.R.C.S., \\ NORWICH.
}

IN investigating these cases it is necessary to bear in mind that they only represent perforating wounds of a certain degree of 
severity, cases in which the eye has not been so severely injured as to necessitate its immediate removal ; in the latter cases the eye has, of course, been removed before the patient reaches England. These patients under consideration had all been sent to the 2nd London General Hospital and the large majority of all the perforating wounds of the globe that were sent to that Hospital are included in these figures ; the number of cases is surprisingly small considering that up to June, 1918, this Hospital was the only Military one in London with special ophthalmic beds, and I think it indicates that in most cases, if a missile in this war penetrated an eye, the eye was so severely injured that it had to be excised as soon as possible.

In 58 cases the left eye was penetrated and in 48 the right eye.

In 24 of the 106 cases a foreign body.was removed with a magnet, in the majority of cases a Haab magnet, before the men left France; but a number of foreign bodies were successfully removed with the ring magnet after the cases reached England. Of these 24 eyes which had foreign bodies removed, 4 were subsequently excised before leaving hospital ; 6 regained some useful vision varying from $3 / 60$ to $6 / 9$; the other 14 were practically blind but remained quiet, and therefore better, from a cosmetic point of view, to the patient than an artificial eye.

Of the remaining 82 eyes, $\mathrm{X}$-ray ${ }^{*}$ reports of 48 gave a negative result in 14 and a positive result in 34 , of which the foreign body was extraocular in 12 and intraocular in 22 cases. Of these 22, the eye was excised in 9 cases at intervals varying from 6 to 38 days after injury, with one exception when the eye was removed 17 months after injury on account of pain : of the remaining 13, 9 left hospital with the eyes quiet but vision of perception of light only and mostly with low tension ; 1 died after an operation on the lower jaw, leaving 3 eyes containing foreign bodies with vision as follows, $3 / 60,6 / 36$ (foreign body seen in vitreous with ophthalmoscope) and 6/9 (minute foreign body lying on the iris); in these 3 cases the foreign bodies were of course non-magnetizable.

In 7 cases where the foreign body had penetrated both walls of the globe and was lying in the orbit, none had to be excised before the men left hospital, but the best vision recorded was "fingers at 3 feet."

Seat of Perforation. Wholly within cornea 36, corneo-scleral margin (limbal) 37, sclera 28, not mentioned 5 . Of the 36 corneal perforations, 14 got vision between $6 / 60$ and $6 / 6$, that is, 39 per cent. with useful vision.

Of the 37 corneo-scleral perforations only 4 got vision between $6 / 36$ and 6/12, that is, just under 11 per cent. with useful vision. Of the 28 scleral perforations, 7 got vision between .6/60 and 6/9, that is 25 per cent. with useful vision. 
These figures go to confirm the view previously held that wounds in the corneo-scleral region give a less favourable prognosis than wounds of other parts of the globe, and in this respect resemble perforating wounds that occur in civil life: the number of eyes requiring subsequent excision is greater, and the number of eyes regaining useful vision is less in these limbal perforations.

The corneal perforations tend to give the most favourable prognosis, and the scleral perforations take a place exactly equidistant between the corneal and limbal cases in these figures as regards recovery of useful vision.

Injury to lens.-44 cases, 7 of which were in cases of scleral perforation; of these 7, 4 appeared to be concussion cataracts and were very incomplete, a good red reflex remaining all the time the men were under observation, although it is probable that these lenses will eventually become completely opaque; of the other 3 , in 2 cases the cataract was due to direct injury, and the other was merely blood-stained deposits on the back of the lens associated with much vitreous haemorrhage, and therefore not a true lens injury.

The other 37 cases were almost all due to direct injury to the lens ; a definite Vossius ring was noticed in one or two patients.

When these men left hospital only 7 of them had vision of $6 / 60$ or better, but, no doubt, in a number of the cases subsequent needlings would improve the vision, for the majority left hospital before the eyes were sufficiently quiet to warrant any operative interference, it being considered inadvisable to needle these cases for at least six or nine months after injury as a general rule. Of the 7 with useful vision, all but one had been needled.

Prolapse of iris. - There were 50 cases with this complication, of which 12 came to excision of the eye, and 11 obtained vision between $6 / 60$ and $6 / 9$, that is, 22 per cent. regained useful vision, a somewhat high percentage for this dangerous complication, and due no doubt to the prompt attention that many of them received in France, the prolapsed iris being excised in nearly all cases as soon as possible.

Enucleation.-In 25 cases:-4 perforation scleral, 14 per cent of the scleral cases: 10 perforation limbal, 27 per cent. of the limbal cases : 7 perforation corneal, 19 per cent. of the corneal cases.

Nature of accident. - 67 due to explosion of shell and splinters hitting eye ; 19 due to accidents such as occur in civil life ; 9 due to bursting of hand bomb or rifle grenade; 7 due to detonators; 4 due to ricochet of fragments of metal from bullets, or to pieces of stone, earth, etc., striking the eye after being hit by a bullet; probably also some of the 67 mentioned as due to shell explosion were caused in this way.

To consider the 19 accidental injuries, 6 occurred while the 
men were chopping wood for incinerators, and in at least one case the man was using his bayonet for the purpose!; two were cases of rupture of the globe from a blow by a man's fist; the others mostly due to small pieces of metal flying into the eye while using hammer, chisel, pick, etc., and one or two to ends of barbed wire catching the eye. In these 19 cases where the force of the penetrating body was not very great, one would expect to get better results than in the other cases, where the penetrating body being in most cases a fragment of shell, would be travelling with great force, sufficient in several cases to perforate both walls of the globe and to come to rest behind it in the orbit. This view is to some extent borne out by the figures, which show 7 out of the 19 accident cases getting vision between $6 / 60$ and $6 / 9,37$ per cent.; whereas of the other 87 shell cases, 17 obtained the same degree of vision, just under 20 per cent. Of the 19 cases, 4 were excised, two of them owing to panophthalmitis.

Sympathetic ophthalmia.-These 106 cases support the opinion now generally held that the risk of this disease supervening on perforations of the globe is very slight; the cases that have occurred as the result of injuries in this war are remarkably few, and I think I am right in saying that only one other case, beside the one in this series about to be described, has occurred in this hospital out of several thousand eye casualties admitted here from abroad.

Details of this case, No. 82 , may be worth while recording: the boy was a lance-corporal, aged 19, wounded by a fragment of shell penetrating the right eye on March 31,1918; the wound of entrance in the ciliary region at 12 o'clock, with prolapse of the iris. Three days after the injury the prolapsed iris was excised and a stitch put in a tear. in the conjunctiva. The surgeon in France made the following note on the field card: "Foreign body passed through the ciliary region and is now in the orbit; question of enucleation to prevent sympathetic ophthalmia left for surgeon in United Kingdom. Vision---No P.L." The day before the iridectomy, that is, two days after injury, Descemet's membrane was covered with fine white spots of "keratitis punctata."

The first note after his arrival in England is on April '14, 1918, R.V. 4/60 : eye injected but not painful, anterior chamber shallow, tension -1 . Vitreous haemorrhage. L.V. 6/5. May 5, a note is made that the eye is quiet and the man is to be "categorised": on May 17, circumcorneal injection appeared in the left eye and some pain was complained of in that eye ; a few doubtful spots of "keratitis punctata " were seen. The right eye was immediately excised on the 47th day after the injury. The following day intravenous galyl was given, and subsequently six other injections at intervals of about a fortnight, which unfortunately did not prevent a severe attack of iridocyclitis, lasting somefour months, which reduced vision to "hand move- 
ments " with subsequent improvement to about $1 / 60$ in a good light.* It was thought that the galyl had some beneficial eftect in checking the disease, and the following additional remedies were all tried without any great success : Locally, atropin followed by eserin on account of the rise of tension, and later, dionin, hot fomentations and compresses, leeches to the temple, massage through the closed lids in the later stages: by mouth, salicylates for a mouth followed by perchloride of mercury, together with mercurial inunctions, and later hypodermic injections of pilocarpine in increasing doses daily, for ten days. Eventually the active trouble slowly subsided, the injection and pain disappeared, and when last seen in February, 1919 , the eye was quite quiet, tension about normal; there was a partial red reflex and he could just see to read and write letters in a good light : the chief cause of the poor vision then appeared to be organised inflammatory exudate in the pupil. No definite "keratitis punctata" ever appeared in this eye.

I wish, in conclusion, to thank Major A. W. Ormond for putting these cases at my disposal.

\section{AN EPIDEMIC OF MACULAR KERATITIS}

\section{BY \\ H. KIRKPATRICK, MADRAS.}

CASES of a peculiar form of keratitis have been seen for the past eighteen months in Madras with increasing frequency until in September of this year the disease has assumed an epidemic character, two or three fresh cases being met with every day.

The type of keratitis somewhat resembles superficial punctate keratitis, but differs in some respects from descriptions of that disease, being distinctly more macular than punctate in character. It has taken three main forms in all of which the opacity appears to be situated in the superficial layers of the substantia propria, Bowman's membrane, and the deeper layers of the corneal epithelium. In none of these does the corneal surface stain with fluorescin.

The symptoms complained of are loss of vision, the appearance of a white spot on the cornea, and occasionally lacrimation and irritation.

The first type is a superficial punctate keratitis and in it small

${ }^{*}$ Since the foregoing was written the patient has been seen on August 28, 1919. V. was then "fingers at 3 feet," eye not injected but painful at intervals; anterior chanber almost non-existent, tension raised, partial red reflex. I fear that he will probably lose what vision he has owing to the secondary glaucoma. 